\title{
Amores Perros
}

ISSN 2462-7518

\section{*MTRA. Krizia Said Castagno ${ }^{1}$}

Como todos sabemos, el 19 de septiembre del presente año, un terremoto sacudió México, el epicentro fue a 12 kilómetros de Axochiapan, en el limite del Estado de Morelos y Puebla. Esto provocó varios derrumbes en esos dos Estados y en la Ciudad de México (lugares más afectados por el sismo).

\section{"Mexicanos al grito de guerra"}

Segundos después de que el sismo de 7.1 escala de Richter finalizara, los mexicanos mostraron fortaleza y unidad. La gente mexicana dejo a un lado su vida para ayudar en todo lo posible a otras personas y animales.

Gente abriendo sus automóviles para dar carga gratuita a los celulares para quien lo necesite, puestos de tacos ambulantes regalando comida, gente con discapacidad ayudando a recoger escombros de los edificios derrumbados, niños repartiendo comida a rescatistas, las redes sociales de plataforma para comunicar en que punto de la ciudad se necesita ayuda, desde comida hasta herramientas para rescate. Mexicanos dando todo lo que pueden dar y más.

Pero no solo los civiles son los héroes de esta historia que aún no termina, las cámaras del mundo se las robo Frida.

Una labrador que es uno de los canes rescatistas de la Secretaría de Marina Armada de

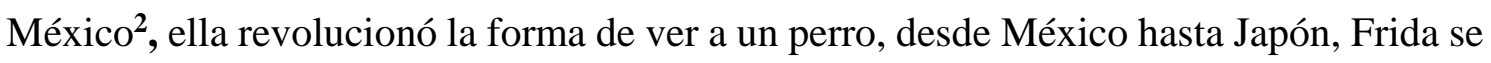

\footnotetext{
1 * Máster en Derecho Animal y Sociedad. Universidad Autónoma de Barcelona. Licenciatura en Comunicación Audiovisual. Universidad del Claustro de Sor Juana, Ciudad de México.

2 Secretaría de Marina Armada de México https://www.gob.mx/semar
} 
ha convertido en icono, tanto que en Japón, en la estatua del famoso "Hachiko 3", la gente la vistió con el uniforme de Frida, con un chaleco que dice "Marina" como lo porta ella.

Los Simpson, no pasaron desapercibidos, compartieron en su cuenta de Twitter un homenaje a esta labrador.

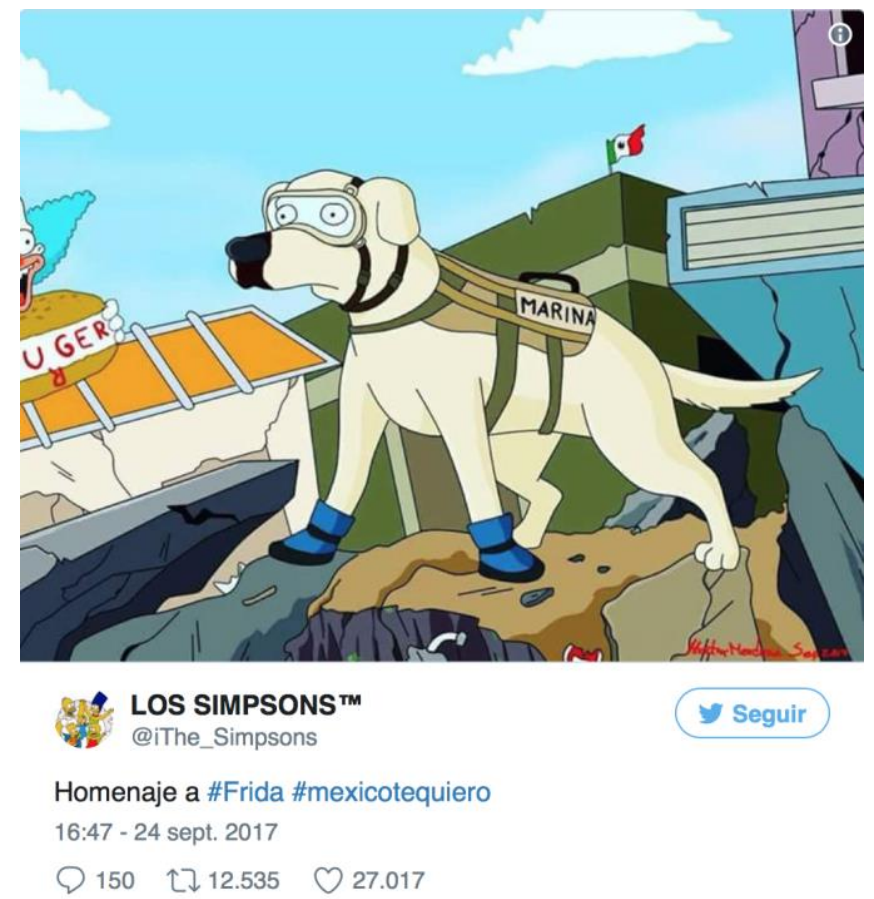

No es para menos, Frida ha rescatado a lo largo de su vida a 52 personas, de acuerdo con Notimex ${ }^{4}$. Pero no solo es Frida la única que ha salvado vidas humanas en este terremoto, ella tiene a dos compañeros rescatistas llamados Eco y Evil que también se han convertido con ella en héroes nacionales.

\footnotetext{
3 “Colocan chaleco de 'Marina' a estatua de Hachiko en Japón" http://www.excelsior.com.mx/de-lared/2017/09/26/1190770 (Ultima visita 27 septiembre 2017)

${ }^{4}$ Notimex http://www.notimex.gob.mx/mexico
} 


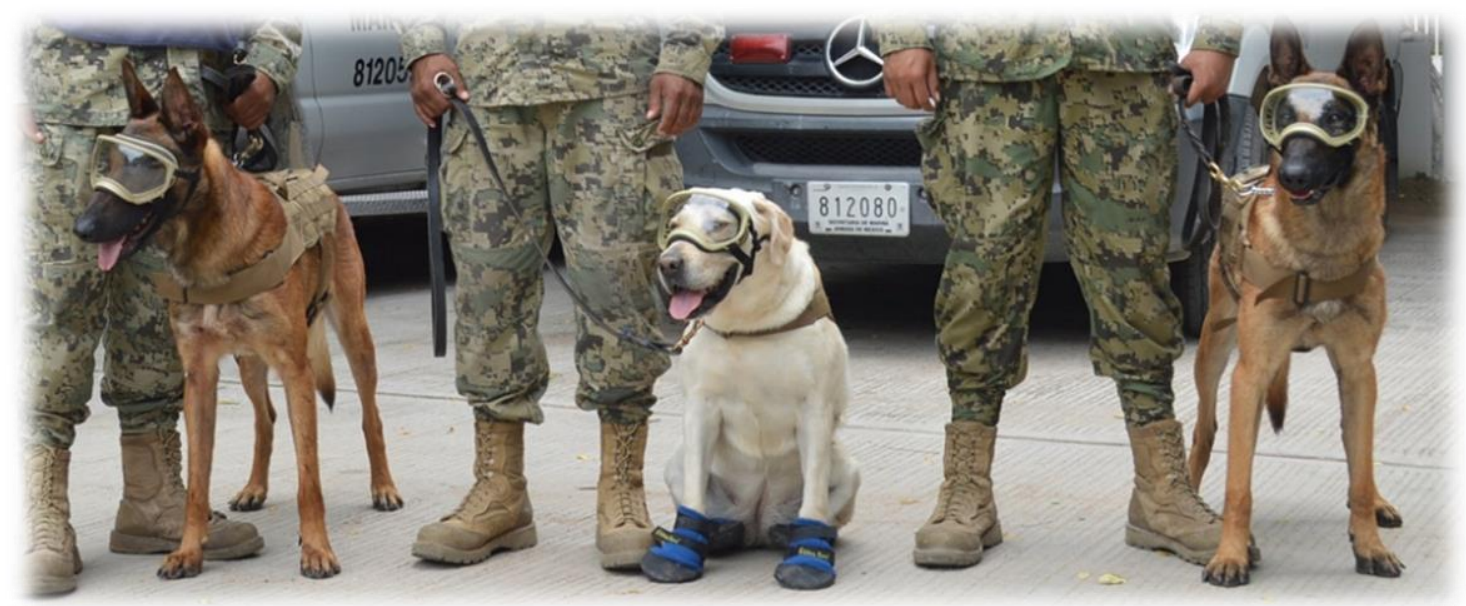

10 Sep. 2017 (Notimex-Nelly Segura).- "Evil", "Frida" y "Eco"

También existen otros perros rescatistas que han estado ayudando a salvar vidas, mencionaremos a unos cuantos:

Hueso esta dentro del Programa de Voluntariado Canino para Emergencias de la Cruz Roja Mexicana, el cual fue un perro que vivió en situación de calle, como la mayoría de los perros en la Ciudad de México, este can llego a la institución en el cual fue acogido.

Titán, Aleka y Kublay este ultimo es un oficial canino de la Policía.

También están Mina, Gala, Baco y Gery de La Unidad de Rescate Canino de la UNAM que pertenecen a la Organización Internacional de Perros de Búsqueda y Rescate.

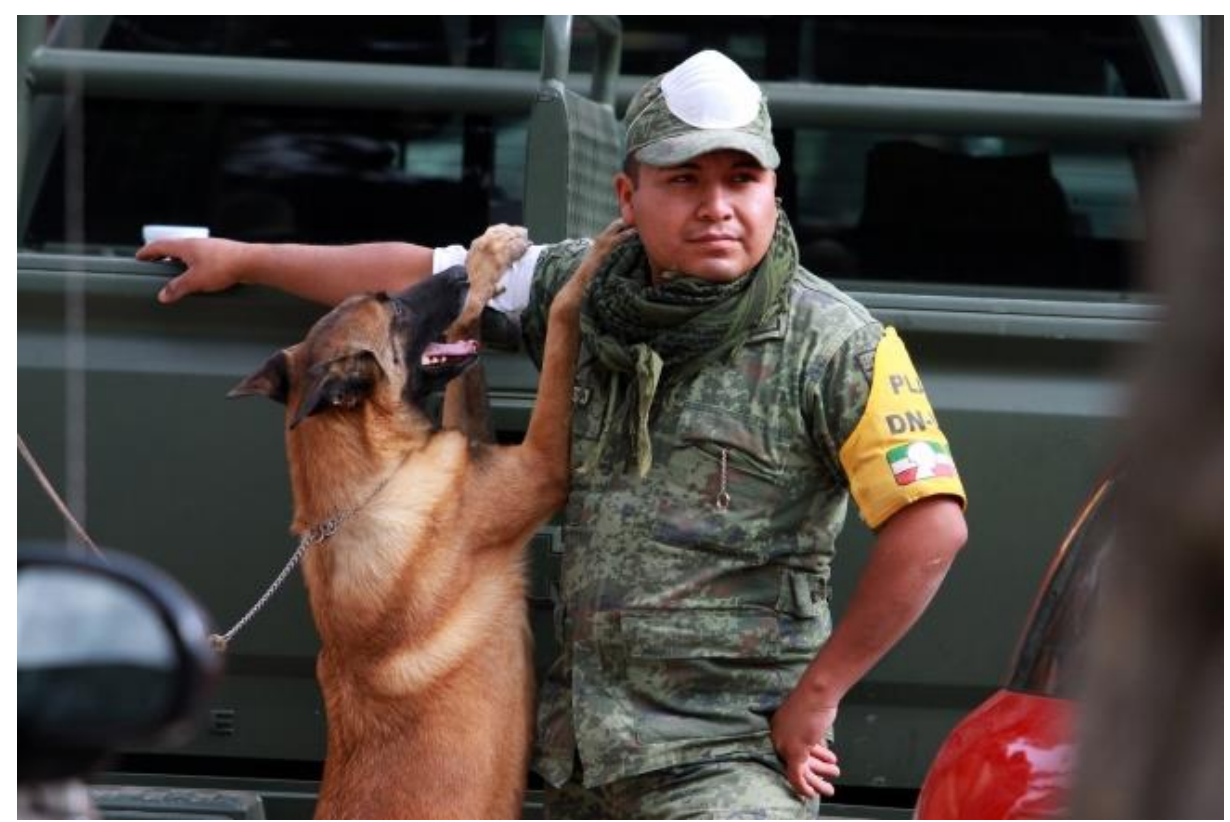

México, 20 Sep 2017 (Notimex-Francisco Estrada).- Binomios caninos del Ejército Mexicano 


\section{dA derecho ANIMAL la web center de los animales con derecho}

Chichí es un pastor belga del Estado de Chihuahua, Balto otro pastor belga que viene de Oaxaca, ${ }^{5}$ y Humo que forma parte del grupo de elementos de la Coordinación Municipal de Protección Civil de Aguascalientes.

Cuando la gente comprobó que verdaderamente "el perro es el mejor amigo del hombre", se comenzó a compartir esta frase "A quienes piensan que se pierde el tiempo rescatando perros, se les olvido que hay perros rescatando personas." Frase que esperamos que llegue a las personas y haga conciencia sobre el maltrato y abandono animal.

\footnotetext{
${ }^{5}$ El Financiero http://www.elfinanciero.com.mx/nacional/no-solo-es-frida-estos-son-los-heroes-caninosdel-sismo.html 